\title{
RECENT DEVELOPMENTS IN MONETARY POLICY ANALYSIS: \\ THE ROLES OF THEORY AND EVIDENCE
}

\author{
Bennett T. McCallum \\ Working Paper 7088 \\ http://www.nber.org/papers/w7088 \\ NATIONAL BUREAU OF ECONOMIC RESEARCH \\ 1050 Massachusetts Avenue \\ Cambridge, MA 02138 \\ April 1999
}

This paper was prepared for the conference "Theory and Evidence in Macroeconomics," held October 1517, 1998, in Bergamo, Italy. For helpful suggestions and criticism, I am indebted to Marvin Goodfriend, Jim Hartley, Bob Hetzel, Bob King, Mary Morgan, and Edward Nelson. The views expressed herein are those of the authors and do not necessarily reflect the views of the National Bureau of Economic Research.

- 1999 by Bennett T. McCallum. All rights reserved. Short sections of text, not to exceed two paragraphs, may be quoted without explicit permission provided that full credit, including ${ }^{\circledR}$ notice, is given to the source. 
Recent Developments in Monetary Policy Analysis:

The Roles of Theory and Evidence

Bennett T. McCallum

NBER Working Paper No. 7088

April 1999

JEL No. E50, E60, B41

\begin{abstract}
Both academic thinking about monetary economics and the practice of monetary policy have changed dramatically since 1971-1973, when the rational expectations revolution was beginning and the Bretton Woods system was crumbling. The present paper considers whether the various changes that have taken place were influenced primarily by economic theory or by empirical evidence-or by a combination of the two.

Monetary economics, like macroeconomics more generally, passed through the rational expectations period into one dominated by real business cycle (RBC) analysis, which denies monetary policy any significant role in the generation or the dampening of cyclical fluctuations in crucial real variables. Recently, however, the analysis of monetary policy by both academic and central bank economists has been increasingly conducted in small quantitative structural models that combine the optimizing aspect of $\mathrm{RBC}$ analysis with various assumptions implying real effects of monetary policy actions due to slow adjustment of nominal prices. These models therefore attempt to combine rather strict theoretical discipline with features that permit an enhanced degree of empirical veracity. It is apparent, accordingly, that both theoretical and empirical analysis have been essential in bringing about alterations in monetary policy analysis between 1971-1973 and 1998 .
\end{abstract}

Bennett T. McCallum

Graduate School of Industrial Administration

Carnegie Mellon University

Pittsburgh, PA 15213

and NBER

bm05@andrew.cmu.edu 


\section{Introduction}

Academic thinking about monetary economics-as well as macroeconomics more generally—has altered drastically since 1971-1973 and so has the practice of monetary policy. The former has passed through the rational expectations and real-business-cycle revolutions into today's "new neoclassical synthesis" whereas policymaking has rebounded, after a bad decade following the breakdown of the Bretton Woods system, into an era of low inflation that emphasizes the concepts of central bank independence, transparency, and accountability while exhibiting substantial interest in the consideration of alternative rules for the conduct of monetary policy. ${ }^{1}$

My assignment in this paper is to consider the roles of economic theory and empirical evidence in bringing about these changes - in particular, changes in policy formulation. Have they been driven primarily by theoretical reasoning or by accumulated evidence? As a related matter, has the evolution reflected health or sickness in the macro-monetary branch of economic science?

In discussing actual monetary policymaking, there is a difficulty stemming from the possibility that in practice policy choices are dominated by responses to current political pressures, with economic reasoning of any form playing a strictly subordinate role in the thought processes of voting members of policy-making bodies such as the United States Federal Open Market Committee. There is reason to believe, however, that economic analysis has been playing an increasing role in monetary policy considerations and, in any event, there would be little for economists to discuss if we were to conclude that actual policy is independent of such analysis. Consequently, most of the discussion below will take writings of central bank economists, together with official publications 
such as inflation reports, as providing some indication of actual monetary policy practices.

Also, it should be admitted at the outset that evaluation of the relative contributions of theory and evidence is extremely difficult. In fact, a proper quantitative evaluation is probably impossible, since economic science evolves by way of a complicated back-and forth interaction of theoretical and empirical considerations. Moreover, these considerations are often combined in the work of a single analyst; for example, most of the researchers listed below in Table 1 rely on such a combination in their own work. Consequently, some of this back-and-forth takes place within the minds of individual researchers and thus may not show up at all in the exposition of papers written to report results. Under such circumstances, it is clear that measurement of the relative contributions of theory and evidence must be highly problematic, at best. Accordingly, what is presented in this paper might be regarded more as a number of observations relevant to the issue, rather than as an actual evaluation. My hope is that these observations will shed some light on the evolution of monetary analysis while establishing that both theory and evidence have played important roles.

The outline of the paper is as follows. In Section 2, general analytic trends in macroeconomics will be briefly outlined as a background. Then Section 3 takes up the evolution of monetary policymaking in practice and Section 4 does the same for the formal analysis of monetary policy. Section 5 treats a special topic and Section 6 concludes. 


\section{Trends in Macroeconomics, 1973-1998}

The years 1971-1973 make a good starting point for our discussion because they mark sharp breaks in both macroeconomic thinking and in institutional arrangements relevant to the conduct of monetary policy. In terms of institutions, of course I have in mind the breakdown of the Bretton Woods exchange rate system, which was catalyzed by the United States's decision of August 1971 not to supply gold to other nations' central banks at $\$ 35$ per ounce. This abandonment of the system's nominal anchor naturally led other nations to be unwilling to continue to peg their currency values to the (overvalued) U.S. dollar, so the par value exchange-rate agreements disintegrated. New par values were painfully established in the December 1971 meeting at the Smithsonian Institution, but after a new crisis in February 1973 the par-value system crumbled in March 1973 and has not been reassembled as of $1998 .^{2}$

In terms of macroeconomics, the years 1971-1973 featured the publication of six papers that initiated the rational expectations revolution. The most celebrated of these, certainly, is Lucas's (1972a) “Expectations and the Neutrality of Money,” but his (1972b) and (1973) were also extremely influential as were Sargent's (1971) and (1973).

Curiously, however, the first publication to use rational expectations in a macro-monetary analysis was none of these but rather Walters (1971), which has apparently had almost no influence. $^{3}$

At first there was much resistance to the hypothesis of rational expectations, partly because in macroeconomics it was initially associated rather strongly with the policy-ineffectiveness proposition. ${ }^{4}$ There were also several other misconceptions, one of which continues today in the argument that it is implausible that all of an economy's 
agents would believe in the particular model of the economy being used by the analyst. ${ }^{5}$ Actually, that is not the assumption required for rational expectations. The latter presumes instead that agents form expectations so as to avoid systematic expectational errors in actuality, which implies that they behave as if they knew the structure of the actual economy. Then expectations will agree with the analyst's model of the economy, but the reason is that this model is by construction the analyst's best attempt to depict the true structure of the economy (otherwise, he/she would use a different model).

Be that as it may, the hypothesis of rational expectations (RE) gradually swept the field in both macroeconomics and microeconomics, a major reason being that it is almost certainly unwise for policy to be conducted under the presumption that any particular pattern of expectational errors will prevail in the future - and ruling out all such patterns implies that expectational errors are orthogonal to information sets (i.e., implies rational expectations). During the late 1970s there was much interest in alternative specifications of price adjustment behavior, since with RE some but not all forms of price adjustment behavior will lead to policy ineffectiveness. Around 1980, however, such research virtually ceased (which is not to say that work with models including slow price adjustments—e.g., Taylor (1989)—ceased). Other topics involving consumption/saving and labor supply behavior became popular for a while, notable contributions including Hall (1978), Hansen and Singleton (1982), and Mankiw, Rotemberg, and Summers (1985).

Then shortly following the appearance of Kydland and Prescott (1982), the era of real-business-cycle (RBC) analysis began. ${ }^{6}$ For the next dozen years, a large fraction of all research by leading macroeconomic analysts involved $\mathrm{RBC}$ reasoning or issues in one 
way or another, pro or con. ${ }^{7}$ In standard RBC analysis it is assumed that price adjustments take place very quickly so that, for practical purposes, there is continuous market clearing for all commodities_-including labor-in which case monetary policy actions will in most models have little or no effect on real macroeconomic variables at cyclical frequencies. Typically, moreover, the RBC models imply that cyclical fluctuations that are observed in real variables are the consequence of technology shocks, not real shocks to preferences or government fiscal variables. Now, of course this has been a highly controversial hypothesis and I am on record as finding it quite dubious (McCallum, 1986, 1989). But it would be wrong to be altogether negative about RBC analysis because much of it has been devoted to the development of new tools of theoretical and empirical analysis, tools that can be employed without any necessary adherence to the RBC hypothesis about the source of cyclical fluctuations.

In recent years, moreover, these tools have been applied in precisely this fashion. Thus a major movement has been underway to construct, estimate, and simulate models in which agents are depicted as solving dynamic optimization problems and interacting on competitive —or, more often, monopolistically competitive—-markets, but with some elements of nominal price or wage "stickiness" built into the structure. The match between these models and actual data is then investigated, often by quasi-RBC procedures, for both real and nominal variables and their interaction. Thus the objective of this line of work is to combine the theoretical discipline of RBC analysis with the greater empirical veracity made possible by the assumption that nominal prices do not adjust instantaneously. ${ }^{8}$ Basically, the attempt is to develop a model that is truly 
structural, and therefore immune to the Lucas (1976) critique of econometric policy analysis.

The mere description of these developments in macroeconomics makes it apparent that they have been driven by a combination of theoretical and empirical impulses. The rational expectations onslaught was primarily theoretical in origin, building upon recognition of the fact that all other expectational hypotheses permit systematic (hence correctable) expectational errors. But the logical basis for the upsurge of the RBC movement can be viewed as principally empirical. ${ }^{9}$ Here the point is that $\mathrm{RBC}$ models are in essence equilibrium business cycle models of the type promoted by Lucas (1972a, 1975) but with the monetary shocks eliminated and technology shocks emphasized. And this change in emphasis came about, it can be argued, largely because empirical analysis of various types suggested that the cyclical real effects of monetary policy shocks were in fact very small in relation to the overall variability of output and employment. Some crucial studies providing such evidence were Sims (1980), Litterman and Weiss (1989), Eichenbaum and Singleton (1986), and Nelson and Plosser (1982). ${ }^{10}$

Then there came the more recent movement to incorporate gradual price adjustment_- "sticky prices" — into optimizing macro models. By its very nature, the impetus for this movement must have been mainly empirical. For there is no body of theory that tells us that price behavior is sticky; to the contrary it is rather difficult to incorporate sticky prices in a model that stresses optimizing general equilibrium theory. ${ }^{11}$ Thus it has to be the force of evidence that has brought about this important change. Moreover, I think it is only fair to recognize that the RBC movement has itself been 
strongly concerned with empirical veracity, even though in that regard its preferred measures have been quite different from those used in orthodox time series econometrics. With respect to these measures a few brief words may be appropriate before we move on. The "standard" set of RBC measures was established in the famous KydlandPrescott (1982) paper, which focused on three sets of second moments for variables that had been "detrended." These were: (i) variances of important real variables including output, labor input, average labor productivity, consumption, investment, and capital; (ii) correlations with output of the other variables listed in (i); and (iii) autocorrelations and, to a lesser extent, lead and lag correlations with output. ${ }^{12}$ Thus the RBC empirical verification program has been to assess the conformity of these measures as generated by RBC models with actual values pertaining to quarterly data for the USA and other economies.

It has been argued by many analysts that these measures provide an inadequate basis for judging the veracity of a macroeconomic model. One problem is that a model may match the data nicely according to the second-moment measurers (i), (ii), and (iii) and yet fail dramatically to fit the data in other respects, as illustrated by Altug (1989) and Watson (1993). In this regard there now exists a sizeable literature on the topic of "calibration vs. estimation."13 A different type of concern is that the production function residuals (e.g., Prescott, 1986), on which the RBC analysis relies, may not be measures of technology shocks at all, but may instead reflect primarily phenomena of an entirely different origin. Some evidence pointing rather strongly in that direction has been presented by Evans (1992), Basu (1996), and Gali (1997). Also, Cogley and Nason (1995) and others have shown that the dynamic properties of typical RBC models come 
almost entirely from the properties of the stochastic process assumed to generate the technology shocks, rather than from the modeled behavior of agents.

\section{Developments in Monetary Policy}

The 1971-73 collapse of the Bretton Woods system created, for the first time in history, a situation in which the world's leading central banks were responsible for conducting monetary policy without an externally-imposed monetary standard (often termed a "nominal anchor"). Previously, central banks had normally operated under the constraint of some metallic standard (e.g., a gold or silver standard), with wartime departures being understood to be temporary, i.e., of limited duration. Some readers might not think of the Bretton Woods system as one incorporating a metallic standard, but by design it certainly was, since the values of all other currencies were pegged to the U.S. dollar and the latter was pegged to gold at $\$ 35$ per ounce. ${ }^{14}$ In practice, United States officials_-Treasury and Federal Reserve — did not treat the \$35/oz standard as if it were a constraint. This was possible initially because the large devaluation of the dollar relative to gold in 1933-34 had left the dollar undervalued, so several years of postwar inflation could therefore take place before the dollar became overvalued relative to gold-i.e., until the free market dollar price of gold began to significantly exceed $\$ 35 / \mathrm{oz}$. But the effects of these years of mild inflation did gradually accumulate and by 1961 the market price of gold had risen (the value of the dollar had fallen) to about $\$ 35 / \mathrm{oz}$. Various patch-up attempts were made to permit the U.S. to continue to conduct policy without conforming to the requirements of the official standard, but another 10 years of slow but steady U.S. inflation generated an unsustainable position—so the system collapsed. 
Faced with the responsibility of establishing a monetary standard of their own design, the world's central banks did not perform well at first and inflation reached levels that were unprecedented for a sustained period without any widespread war. Germany and Japan began to get inflation under control by the middle 1970s but it remained high in the other G-7 nations. In the U.S. and the U.K. there was a tendency for central banks to deny that their own behavior was an essential ingredient to the inflation process ${ }^{15}$ and considerable importance was attached by central banks to employment, output, and other real macroeconomic objectives. The exact nature of central bank thinking during these years is a matter of dispute, ${ }^{16}$ but I am myself inclined to share the judgment of Taylor (1996), who depicts central bankers as acting under the influence of 1960s academic ideas that posited the existence of a long-run and exploitable Phillips-type tradeoff between inflation and unemployment rates. ${ }^{17}$

During the 1970s, there was considerable discussion of policy regimes featuring money growth targets. In Germany, the Bundesbank adopted a monetary targeting strategy that has, with some modifications, been officially employed ever since. The other large-nation central bank that was most successful in avoiding inflation in the late 1970s and 1980s, the Bank of Japan, also apparently gave some emphasis to monetary targets (although in this case the extent of dedication to this strategy was apparently smaller). In the United States, monetary growth targets were given official status by the Humphrey-Hawkins Act of 1975, but evidently played a rather small role in actual policymaking until October 1979. ${ }^{18}$ Then on October 6 the Fed began its so-called "monetarist experiment," i.e., the period (ending in July 1982) during which M1 targets were actively pursued by means of a new operating procedure that featured a 
nonborrowed reserves instrument. Interest rates quickly rose dramatically, but the effort foundered during 1980 as a result of the selective credit controls that were imposed and then quickly removed. Finally, a period of genuine monetary stringency was begun at the end of 1980 and maintained until the middle of 1982. In response, inflation fell quite rapidly—as did output and employment. ${ }^{19}$

From 1983 until 1990, U.S. inflation fluctuated gently around a midpoint of about 4 or 4.5 percent per year. A monetary tightening during 1989 interacted with the Persian Gulf oil crisis of 1990 to begin another recession that was mild but lengthy. By late 1992, U.S. inflation had declined further to the 2-3 percent range that has persisted since. Whether the Fed was deliberately seeking a reduction in the trend inflation rate during 1989-1990 is a matter of some dispute.

In terms of operating procedures, the Fed gradually reverted after August 1982 to a scheme that centers on the Federal funds rate as its instrument (or "operating target"). In addition, interest rates have come to receive more attention-via the term structure but also long-term rates in an unaugmented state-as indicators of monetary conditions. Thus monetary aggregate growth rates have been downgraded in policymaking significance to the point that the biannual congressional hearings, because they legislatively require reference to these figures, always include a few minutes of distinct awkwardness in the Fed's testimony.

Outside the USA, a major development has been the emergence of the European Monetary Union. Partly because of the so-called convergence criteria needed to qualify for participation in the single-currency Euro scheme, to be guided by the ECB (European 
Central Bank), inflation rates across Europe have fallen remarkably, averaging close to 1.0 percent for the most recent years (1996-98).

Also highly noteworthy has been the arrival of inflation targeting as a new framework for the conduct of monetary policy. Actually, most central banks, among those that are not constrained by formal exchange rate commitments, do not adhere to any clear-cut and announced procedures in conducting monetary policy. But of those that have adopted explicit policy frameworks, virtually all have opted for targets expressed in terms of inflation rates, not money stock or nominal income growth rates. ${ }^{20}$ Most notable, probably, is the arrangement in New Zealand, which came first and which stipulates that the central bank governor can be removed if the agreed-upon 0-2\% inflation target band is not met. ${ }^{21}$

Overall, the most fundamental change since the 1970s has been the assumption of responsibility by central banks for performance in terms of inflation rates. In 1998, it would be extremely surprising to run across a central bank statement that discussed medium-term inflation prospects in a manner suggesting that these are unaffected by monetary policy behavior. So, even though we are here discussing practice and not analysis, one could ask whether theory or evidence has been more responsible for the change in opinion. In this regard there is a "multicollinearity problem" because, as it happens, both theory and evidence have pointed strongly in the same direction, i.e., toward the proposition that there is no permanent stimulus to real variables from monetary leniency so that sustained easy conditions will produce just inflation, without any lasting boost to output or employment. There is of course some formal econometric evidence in this regard, ${ }^{22}$ but even more influential to policy makers, probably, was the 
informal perception of the 1970s as a decade of experience with high inflation accompanied by no enhancement in terms of output and employment. Thus we have theory, formal evidence, and informal "experimental" evidence all pointing in the same direction—-toward the idea that from a long-term perspective monetary policy's main influence is on growth of the price level with little or no lasting effect on real output's level or growth rate. From this conception it is a natural step to view inflation prevention as the main macroeconomic duty of a modern central bank, with a secondary objective of dampening cyclical fluctuations, and today's general policy climate falls into place.

\section{Monetary Policy Analysis}

We now turn to the topic of central concern in this paper, analysis of monetary policy arrangements by economists-i.e., by monetary economics specialists in universities, central banks, and other analytical organizations. ${ }^{23}$ In that regard it is quite gratifying to report that in recent years there has been a large amount of interaction between central bank and academic analysts, so that today (August 1998) one would be hard-pressed to tell, for many research papers, whether a particular one had been written by members of one group or the other. ${ }^{24}$ To illustrate that point, as well as others to be made below, it will be useful to refer to two major conferences held in the first half of 1998. The first of these is an NBER conference on "Monetary Policy Rules" held January 15-17 in Islamorada, Florida, and the second is a Riksbank-IIES conference "Monetary Policy Rules" held June 12-13 in Stockholm. Since the conference titles are the same, they will be referred to below as the NBER and Riksbank conferences. The former was organized by John B. Taylor (Stanford University), the latter by Claes Berg 
(Sveriges Riksbank) and Lars E.O. Svensson (Institute for International Economic Studies, Stockholm University).

Paper authors, discussants, and panelists at these two conferences are listed in Table 1. It will be noted that there is some overlap in the lists. More importantly, it will be noted that there is substantial participation by both academic and central bank economists in both conferences, especially the Riksbank's. ${ }^{25}$ To verify the similarity in concerns and techniques exhibited by central bank and academic authors, the reader is invited to sample the papers themselves. They are forthcoming in an NBER conference volume and an issue of the Journal of Monetary Economics; as of August 1998 virtually all the papers could be downloaded from NBER or IIES home pages on the world wide web.

The situation just described is vastly different from that obtaining as recently as the middle 1980s, when academic and central bank economists had much less interaction and much less similarity of viewpoint. ${ }^{26}$ If one introspects about reasons for the change, one can easily think of several contenders, among which are some that involve adjustments on the part of both groups. One fact is that several (regional) Federal Reserve Banks have, since the late 1970s, employed academic economists as consultants, a practice that makes each group more familiar with research assumptions held to be essential by the other-e.g., academics have become more knowledgeable about realistic operating procedures while central bank economists have become more comfortable with analysis utilizing rational expectations. Conferences held by Federal Reserve Banks and some by academics (e.g., NBER and Carnegie-Rochester conferences) have brought 
Table 1

Programs for NBER and Riksbank-IIES Conferences

A. NBER Conference, January 15-17, 1998

1. Bennett McCallum and Edward Nelson, Carnegie Mellon Univ., "Performance of Operational Policy Rules in an Estimated Semi-Classical Structural Model.'”

Discussant: $\quad$ Mark Gertler, New York Univ.

2. Julio Rotemberg, Harvard University, and Michael Woodford, Princeton Univ., "Interest Rate Rules in an Estimated Sticky-Price Model."

Discussant: Martin Feldstein, Harvard Univ.

3. Laurence Ball, Johns Hopkins Univ., "Policy Rules for Open Economies." Discussant: Thomas Sargent, Stanford Univ.

4. Andrew Haldane and Nicoletta Batini, Bank of England, "Forward Looking Rules for Monetary Policy."

Discussant: $\quad$ Donald Kohn, Federal Reserve Board

5. Glenn Rudebusch, FRB of San Francisco, and Lars Svensson, Institute for International Economic Studies, "Policy Rules for Inflation Targeting."

Discussant: James Stock, Harvard Univ.

6. Andrew Levin, Volcker Wieland, and John Williams, Federal Reserve Board, "Are Simple Monetary Rules Robust to model Uncertainty?"

Discussant: Lawrence Christiano, Northwestern Univ.

7. John Taylor, Stanford Univ., “An Historical analysis of Monetary Policy Rules,"

Discussant: Richard Clarida, Columbia Univ.

8. Robert King, University of Virginia, and Alexander Wolman, FRB of Richmond, "What Should Monetary policy Do When Prices are Sticky?"

Discussant: Benjamin Friedman, Harvard Univ.

9. Arturo Estrella, FRB of New York, and Frederic Mishkin, Columbia Univ., "The Role of NAIRU in Monetary Policy: Implication of Uncertainty and Model Selection."

Discussant: Robert Hall, Stanford Univ. 
(Table 1 continued)

B. Riksbank-IIES Conference, June 12-13, 1998

1. Frederic Mishkin, Columbia Univ., "International Experiences with Different Monetary Policy Regimes."

Discussant: Charles Goodhart, London School of Economics and Bank of

England

2. John Taylor, Stanford Univ., "The Robustness and Efficiency of Monetary Policy Rules as Guidelines for Interest Rate Setting by the European Central Bank."

Discussant: Leonardo Leiderman, Bank of Israel

3. Jürgen von Hagen, Mannheim Univ., "Money Growth Targeting."

Discussant: Stephen Cecchetti, FRB of New York

4. Bennett McCallum and Edward Nelson, Carnegie Mellon Univ., "Nominal Income Targeting in an Open-Economy Optimizing Model."

Discussant: Glenn Rudebusch, FRB of San Francisco

5. Dale Henderson with Christopher Erceg and Andrew Levin, Federal Reserve Board, "Output-Gap and Price Inflation Volatilities: Reaffirming Tradeoffs in an Optimizing Model."

Discussant: Stefan Gerlach, Bank for International Settlements

6. Lars Svensson, IIES, "Inflation Targeting as a Monetary Policy Rule." Discussant: Alan Blinder, Princeton Univ.

7. Claes Berg, Sveriges Riksbank, and Lars Jonung, Stockholm School of Economics, "Pioneering Price Level Targeting: the Swedish Experience 193137."

Discussant: $\quad$ Mervyn King, Bank of England

8. Panel Discussion

Alan Blinder, Princeton Univ.; Donald Brash, Reserve Bank of New Zealand; Otmar Issing, European Central Bank; Mervyn King, Bank of England; and Guido Tabellini, Bocconi Univ. 
central bank and academic researchers together more often. Ph.D. graduates of leading universities have taken positions at the Federal Reserve Board and regional Feds and have played crucial roles in the development of Fed models and procedures. ${ }^{27}$ The "Economic Review" publications of Federal Reserve Banks have become more open to articles of a nearly academic style, which has fostered increased understanding in both directions, and more Federal Reserve Banks have encouraged their research staff members to publish in academic publications. And there are still more channels of communication, not as open or as regularly used during the 1960s and 1970s, that could in principle be listed. Also, Taylor's paper (1993) succeeded brilliantly in interesting central bankers in the consideration of rule-guided policy making.

The typical method for conducting monetary policy analysis in the NBER and Riksbank conferences can be summarized as follows. An analytical macroeconomic model is developed that includes three major components: (i) a monetary policy rule that specifies quarterly settings for an interest rate instrument, (ii) an IS-type relation or set of relations that specifies how interest rate changes affect aggregate demand and output, and (iii) a price-adjustment equation or set of equations that specifies how inflation behaves in response to output (measured relative to capacity) and expectations regarding the future. Typically, these models feature rational expectations. They may be estimated by various strategies including the estimation procedure termed "calibration" but, whatever the strategy, an attempt is made by the researcher to develop a quantitative model in which parameter values (including disturbance term variances, covariances, and autocovariances) are consistent with actual time series data. Frequently, some effort is taken to make the policy rule operational, i.e., one that is based on a feasible specification 
of the instrument variable and plausibly available information. Furthermore, in many (but not all) cases the model utilized is obtained by consideration of optimal choices by individual agents in a dynamic and stochastic environment. Then stochastic simulations are conducted using the specified model and alternative policy rules, with summary statistics calculated to represent performance in terms of average values ${ }^{28}$ of various macroeconomic measures such as the mean or variability of inflation, the output gap, ${ }^{29}$ interest rates, etc. ${ }^{30}$ Some models are constructed so that each simulation implies a related utility level for a representative individual agent; in such cases, utility-based performance measures can be calculated.

Having outlined the dominant manner in which monetary policy analysis is currently being conducted, our task now is to discuss changes from the research style or styles prevalent in 1971-73 and then to attempt to attribute these changes to the influence of theory or evidence. Perhaps the most fundamental difference between the procedure outlined above and standard practice as of 1971-73 is the incorporation of rational expectations. Expectations are important in any dynamic analysis, of course, but if these are rational rather than conforming to some fixed distributed-lag structure then they must be treated quite differently in the study of policy rules, as was emphasized in Lucas's famous critique paper (1976). ${ }^{31}$ In particular, the model's equations must not muddle together lagged values from forecasting (expectational) relations and lags in variables due to other causes, such as adjustment costs. This distinction is necessary since, with rational expectations, the coefficients in the forecasting rules will be different with different policy rules — and so cannot be held fixed in comparisons of alternative policy rules. The same is not true of adjustment-cost parameters. 
Now clearly the switch from the fixed-lag to the rational expectations hypothesis was the consequence primarily of theoretical, rather than empirical, analysis. At the time it seemed a rather drastic step, but after the fact it has come to be recognized as an entirely natural extension of the usual approach of neoclassical economic analysis to an area of economic activity (expectation formation) that had previously been treated in a non-standard manner. Today, many economists trained after 1980 appear, empirically, to have difficulty in even contemplating any other expectational hypothesis. Also, it should be remembered that Lucas's critique itself was not new, but merely a (brilliantly persuasive) application of Marschak's (1953) fundamental insight that policy analysis requires a structural (as opposed to reduced-form) model.

There have recently been a few attempts to argue that, whatever the theoretical attractions of rational expectations, evidence suggests that the Lucas critique is of little or no consequence empirically. The most extensive and prominent such argument is perhaps that of Hendry and Ericsson (1991) and Ericsson and Irons (1995), who document that an estimated model of money demand shows no symptoms of parameter change (due to coefficient changes in forecasting equations) across periods with different monetary policy rules in effect. A detailed analysis of these studies is beyond the scope of the present paper, but a basic objection to the Hendry-Ericsson-Irons argument can be presented very briefly. It is simply that money demand relations provide an inappropriate laboratory for the study of Lucas-critique effects. The reason is that standard theoretical analysis of money demand behavior, as represented by, e.g., McCallum and Goodfriend (1987), Lucas (1988), Woodford (1995), Walsh (1998, Ch. 3), and many others, indicates that forecasting (i.e., expectational) relations are not involved in the optimality conditions 
(Euler equations) that are typically termed "money demand functions." 32 In other words, these relations are ones that are not predicted to shift with policy changes, under Lucas critique reasoning. Thus a failure to shift with policy changes is irrelevant to the issue. A much better laboratory for consideration of this issue would be Phillips-curve relationships, in which expectational variables are prominent. ${ }^{33}$

A related but somewhat different empirical criticism of rational expectations analysis has recently been put forth by Fuhrer (1997). In an analysis based upon a price adjustment (Phillips Curve) relation that is formulated so as to nest expectational (forward looking), inertial (backward looking), and mixed specifications, Fuhrer finds that the expectational terms provide statistically insignificant explanatory power: "I find that expectations of future prices are empirically unimportant in explaining price and inflation behavior" (Fuhrer, 1997, p. 349). This would appear to strike a significant blow to the hypothesis of rational expectations, suggesting that expectations are instead formed as fixed-weight distributed lags of past values. My own response to this argument may not be widely accepted, but it has been held for many years (see McCallum, 1980, p.718). ${ }^{34}$ It is that the incorporation of the rational expectations hypothesis is much more important for policy evaluation than at the estimation stage of the research project. It is fairly plausible that systematic expectational errors can be found in data for past years, distant or recent. But it would be unwise — as mentioned above - to expect any given pattern of expectational errors to prevail in the future, especially if policy is designed to exploit this error pattern. But to conduct policy analysis without assuming rational expectations is to design policy in a manner that attempts to do precisely that, i.e., to exploit a particular pattern. Thus it is desirable to design policy under the assumption of 
rational expectations even if one has utilized some other expectational hypothesis in estimating the model utilized. Interestingly, Fuhrer himself often uses rational expectations models in his own policy-analysis studies (e.g., Fuhrer 1996).

Another apparent change in monetary policy analysis since 1971-73 is that such analysis is now typically conducted in terms of a choice among alternative policy rules, as contrasted with the choice of policy actions to be taken in a particular episode. But this change is basically a necessary concomitant of the rational expectations assumption and therefore needs no separate discussion.

Rational expectations does not itself imply the absence of a long-run tradeoff between inflation and unemployment. But analysts, like the policymakers mentioned above, moved during the 1970s to near-unanimous acceptance of the Friedman-PhelpsLucas view that there is no exploitable long-run tradeoff between inflation and output or employment (measured relative to capacity). Undoubtedly, this move was influenced by the same brute experiences as those seen by policymakers, but for analysts there was also some formal econometric work that probably played a role. Thus it was the case that Solow (1969), Tobin (1969), Gordon (1970), and others began quickly to conduct standard tests based on time series regression estimates very promptly after receiving the challenge of Friedman $(1966,1968)$ and Phelps (1967). These first studies suggested, as veterans of the period will recall, that long-run tradeoffs, did exist-that the long-run Phillips curve was not vertical. But after Sargent (1971) and Lucas (1972b) pointed out the logical flaw that invalidates these studies if expectations are rational, other tests conducted in more appropriate ways by Sargent (1973), McCallum (1976), and Barro (1977) indicated that long-run tradeoffs were not present-a position subscribed to in 
subsequent studies by Gordon (1975). Thus empirical evidence (of various types) was probably dominant in bringing about a crucial change in analytical views.

The foregoing should not be taken to imply that there are no remaining disagreements concerning long-run relationships between real and monetary variables. Indeed, there are major differences implied by various types of price adjustment models that are currently in use. For example, the type of price adjustment scheme most frequently discussed in practical policy-making circles is that of NAIRU models, where the name is an acronym for non-accelerating-inflation rate of unemployment. In nontechnical publications_-even including a symposium in Economic Perspectives (Winter 1997) — models of the NAIRU type are often discussed as if they reflected the property known as the natural rate hypothesis $(\mathrm{NRH})$. But the latter, as formulated by Lucas (1972b), asserts that there is no time path of the price level (or the money stock) that would (if maintained) keep output permanently away from its market-clearing natural-rate path. Thus if $y_{t}$ denotes the log of output and $\bar{y}_{t}$ is its market-clearing or natural-rate value, the $\mathrm{NRH}$ asserts that the unconditional expectation $\mathrm{E}\left(\mathrm{y}_{\mathrm{t}}-\overline{\mathrm{y}}_{\mathrm{t}}\right)$ will be unaffected by the selection among monetary policy regimes. Not only will a high inflation rate fail to keep $\mathrm{E}\left(\mathrm{y}_{\mathrm{t}}-\overline{\mathrm{y}}_{\mathrm{t}}\right)$ above zero, but so will an increasing (often termed "accelerating") inflation rate or one with an increasing second (or nth!) difference in $\mathrm{p}_{t}$, the log of the price level. By contrast, models of the NAIRU type typically possess the implication that a maintained increase in the inflation rate, such as $\Delta \mathrm{p}_{\mathrm{t}}=\Delta \mathrm{p}_{\mathrm{t}-1}+\delta$ for $\delta>0$, will keep $\mathrm{E}\left(\mathrm{y}_{\mathrm{t}}-\overline{\mathrm{y}}_{\mathrm{t}}\right)>0$. Indeed, the very name NAIRU suggests this property, for it suggests a stable relationship between the increase in inflation and $\mathrm{y}_{\mathrm{t}}-\overline{\mathrm{y}}_{\mathrm{t}}$. But that 
implies that a properly chosen $\Delta \mathrm{p}_{\mathrm{t}}$ pattern can keep $\mathrm{y}_{\mathrm{t}}-\overline{\mathrm{y}}_{\mathrm{t}}$ above zero permanently, in contradiction to the NRH. ${ }^{35}$

Another prominent class of price adjustment model is the staggered contracts class typified by Calvo (1983), Rotemberg (1982), and Taylor (1980). These also fail to possess the NRH property, but in the opposite direction: they imply that an everincreasing inflation rate will tend to keep output permanently low! While I personally consider this violation to be a mark against these models, one that suggests the presence of some dynamic misspecification, the implications are not nearly so dangerous from a policy perspective as those of the NAIRU class. One price adjustment model that does satisfy the NRH is the "P-bar model" used by McCallum and Nelson (1998). Its main weakness is that it fails to produce strong positive serial correlation in inflation ratesi.e., sticky inflation — which seems to be a feature of quarterly data in the U.S. and elsewhere. However, the only compact model known to me that does tend to generate inflation persistence is that of Fuhrer and Moore (1995), which fails to satisfy the NRH (although it fails by less than the others mentioned above).

A striking feature of the typical models in the NBER and Riksbank conferences is that they include no money demand equations or sectors. That none is necessary can be understood by reference to the following simple three-equation system.

$$
\begin{aligned}
& \mathrm{y}_{\mathrm{t}}=\alpha_{0}+\alpha_{1} \mathrm{E}_{\mathrm{t}} \mathrm{y}_{\mathrm{t}+1}+\alpha_{2}\left(\mathrm{R}_{\mathrm{t}}-\mathrm{E}_{\mathrm{t}} \Delta \mathrm{p}_{\mathrm{t}+1}\right)+\alpha_{3}\left(\mathrm{~g}_{\mathrm{t}}-\mathrm{E}_{\mathrm{t}} \mathrm{g}_{\mathrm{t}+1}\right)+\mathrm{v}_{\mathrm{t}} \\
& \Delta \mathrm{p}_{\mathrm{t}}=\mathrm{E}_{\mathrm{t}} \Delta \mathrm{p}_{\mathrm{t}+1}+\alpha_{4}\left(\mathrm{y}_{\mathrm{t}}-\overline{\mathrm{y}}_{\mathrm{t}}\right)+\mathrm{u}_{\mathrm{t}} \\
& \mathrm{R}_{\mathrm{t}}=\mu_{0}+\mu_{1}\left(\Delta \mathrm{p}_{\mathrm{t}}-\Delta \mathrm{p}^{*}\right)+\mu_{2}\left(\mathrm{y}_{\mathrm{t}}-\overline{\mathrm{y}}_{\mathrm{t}}\right)+\mathrm{e}_{\mathrm{t}}
\end{aligned}
$$

Here equations (1) - (3) represent an expectational IS equation, a price-adjustment relationship, and a Taylor-style monetary policy rule, respectively. The basic variables 
are $\mathrm{y}_{\mathrm{t}}=\log$ of output, $\mathrm{p}_{\mathrm{t}}=\log$ of price level, and $\mathrm{R}_{\mathrm{t}}=$ nominal one-period interest rate, so $\Delta \mathrm{p}_{\mathrm{t}}$ represents inflation, $\mathrm{R}_{\mathrm{t}}-\mathrm{E}_{\mathrm{t}} \Delta \mathrm{p}_{\mathrm{t}+1}$ is the real interest rate, and $\mathrm{y}_{\mathrm{t}}-\overline{\mathrm{y}}_{\mathrm{t}} \equiv \tilde{\mathrm{y}}_{\mathrm{t}}$ is the fractional output gap (output relative to its capacity or natural rate value, whose log is $\left.\bar{y}_{t}\right)$. Also, $g_{t}$ represents the log of government purchases, which for present purposes we take to be exogenous. In this system, $\mathrm{E}_{\mathrm{t}}$ denotes the expectations operator conditional on information available at time $\mathrm{t}$, so $\mathrm{E}_{\mathrm{t}} \Delta \mathrm{p}_{\mathrm{t}+1}$ is the rational expectation formed at $\mathrm{t}$ of $\Delta \mathrm{p}_{\mathrm{t}+1}$, the inflation rate one period in the future.

The basic point at hand is that with $g_{t}$ and $\bar{y}_{t}$ exogenous, and expectations formed rationally, the three equations (1) - (3) are sufficient in number to fully determine the time paths of the model's three endogenous variables, namely, $\mathrm{y}_{\mathrm{t}}\left(\right.$ or $\left.\tilde{\mathrm{y}}_{\mathrm{t}}\right), \Delta \mathrm{p}_{\mathrm{t}}$, and $\mathrm{R}_{\mathrm{t}}$. Thus there is no need for a money-demand equation. ${ }^{36}$ If nevertheless one such as

$$
\mathrm{m}_{\mathrm{t}}-\mathrm{p}_{\mathrm{t}}=\gamma_{0}+\gamma_{1} \mathrm{y}_{\mathrm{t}}+\gamma_{2} \mathrm{R}_{\mathrm{t}}+\varepsilon_{\mathrm{t}}
$$

were appended to the system, it would not be inconsistent with (1) - (3) but would be irrelevant in the sense that it would play no role in determining the behavior of $\mathrm{y}_{\mathrm{t}}, \Delta \mathrm{p}_{\mathrm{t}}$, or $\mathrm{R}_{\mathrm{t}}$. Its role would be merely to determine the amount of money $\left(\mathrm{m}_{\mathrm{t}}\right.$, in $\log$ terms $)$ that would be demanded and which would therefore necessarily be supplied by the central bank in the process of setting interest rates in conformity with the policy rule (3).

It can be seen that the absence of any money demand function-or any money stock variable! - in the prototype system (1) - (3) reflects two properties of the latter. These are that no "real balance" term $m_{t}-p_{t}$ appears in the IS relation (1) and that the interest rate $\mathrm{R}_{\mathrm{t}}$ is used as the policy instrument. So we ask, what are the methodological precepts that lead to those two aspects of (1) - (3)? 
In the case of the second aspect, that $\mathrm{R}_{\mathrm{t}}$ is specified as the instrument variable, the rationale is almost entirely empirical. The fact is that actual central banks in industrial countries conduct monetary policy in a manner that is much more accurately depicted by writing $R_{t}$ rather than $m_{t}$ (even if interpreted as the monetary base) as the instrument or operating-target variable. Thus, such policy rules are studied even by economists who might be regarded as possessing "monetarist" tendencies and possibly even believing that policy might be improved if central banks used $\mathrm{m}_{\mathrm{t}}$ as their instrument (e.g., McCallum and Nelson, 1998).

The first aspect of the system (1) - (3), that no "money" term appears in the IS function (1), is by contrast of an a priori origin. Traditionally, of course, it has been usually presumed in analysis of an IS-LM style that IS functions do not include real balance terms. ${ }^{37}$ But in recent work, the IS relationship has often been of the expectational variety that includes $\mathrm{E}_{\mathrm{t}} \mathrm{y}_{\mathrm{t}+1}$ as in Kerr and King (1996), McCallum and Nelson (1997), and Rotemberg and Woodford (1997). Such relations are obtained from explicit optimization analysis of the dynamic choice problems faced by individual agents, so they have arguably greater claim to theoretical validity than traditional specifications. But in such analyses, the absence of any monetary real-balance variable depends upon the common assumption that separability obtains in the indirect utility function that reflects the transaction-facilitating properties of the medium of exchange (i.e., money). There is, however, no compelling theoretical basis for that assumption, which is presumably made for analytical convenience. Indeed, it could be argued that separability is not very plausible. Accordingly, the absence of any real balance term in (1), and the omission of monetary variables from model (1) - (3), hinges on the presumption that 
nonseparabilities of the relevant type are quantitatively unimportant-i.e., that the marginal utility of consumption is (for a given rate of consumption) virtually independent of the level of real money balances. The justification for that presumption has not been explicitly discussed in the studies cited.

It has been mentioned that the NBER and Riksbank conferences featured considerable agreement among participants concerning research strategy. Furthermore, Taylor (1998, pp. 4-5) argues that there exists a fair amount of substantive agreement; specifically that model simulations at the NBER conference "show that simple policy rules work remarkably well in a variety of situations; they seem to be surprisingly good approximations to fully optimal policies..." and "simple policy rules are more robust than complex rules across a variety of models." Also, "introducing information lags as long as a quarter does not affect the performance of the policy rules by very much." In addition, Taylor mentions other issues about which these studies do not reflect agreement, including: the value of interest-rate "smoothing" terms in the rules; whether responses should be geared to expected feature values rather than currently-observed values; and about measurement of potential or natural-rate output.

One area of disagreement among researchers concerns the distinction between "optimal control" and "robustness" approaches for the design of monetary policy rules. For some analysts, the task of policy rule design is to develop an appropriate macroeconomic model of the economy and then conduct an optimal control exercise to determine what the best policy rule would be for the economy in question. Neither step is trivial, but both represent rather straightforward scientific problems. There would remain the task of convincing actual policy makers to implement this rule, of course, but 
that is a matter of persuasion rather than scientific investigation. Notable examples of this approach are Feldstein and Stock (1994) and Svensson (1997). To other economists, by contrast, a crucial feature of the policymaking process is the lack of professional agreement concerning the appropriate specification of a model suitable for monetary policy issues. Various members of this group would emphasize different portions of a macro model, ${ }^{38}$ but to all in this group it seems hard to avoid the conclusion that agreement upon model specification is predominately absent—and that different models give rise to different alleged implications for policy. Thus these latter economists believe that in practice the optimal control strategy collapses in response to the question, "What is the appropriate model specification?" As a consequence, the approach favored by these analysts is to search for a policy rule that possesses robustness in the sense of yielding reasonably desirable outcomes in policy simulation experiments conducted with a wide variety of models. ${ }^{39}$ It is not necessary that the collection of models all be designed and simulated by a single researcher or research team; the work of Bryant et al (1993) and Taylor (1998) represent studies by over a half-dozen research teams each.

In evaluating candidate policy rules, it would clearly be desirable to have at hand an established specification of the appropriate ultimate goals of monetary policy. In that regard there are several important issues, including whether a CB should keep actual inflation or expected inflation close to some normative value; what that normative value should be (or should it change over time?); and how heavily the variability of output—or is it output relative to capacity (measured how?) or consumption?in relation to the inflation criterion. Of course in optimizing models that are specified at the level of individuals' utility and production functions, the answers to such questions 
are implicit to the solution to the optimal control problem. But again the fundamental difficulty mentioned above intrudes in a crucial manner, for these answers must depend significantly upon the model's specification. Thus the absence of agreement regarding model specification implies that there can be at present no consensus as to the precise goals that are appropriate. In practice, nevertheless, there seems currently to be a substantial amount of agreement about actual CB objectives; namely that most CBs desire to keep realized inflation close to zero (allowing for measurement error) and to keep output (or employment) close to a capacity or natural-rate value that grows with the capital stock, the labor force, and technical progress. As a matter of logic it cannot be rigorously established that these objectives are optimal (from the perspective of individuals' preferences), but it seems a reasonable judgment that they probably provide an appropriate specification of CB macroeconomic goals.

A related research-design issue that has attracted some attention involves the distinction between "instrument rules" and "target rules," in the language of Svensson (1997). Rules of the former type, exemplified by Taylor (1993) and presumed in my foregoing comments, specify period-by-period settings of a controllable instrument variable as in equation (3) above. The latter type of rules, by contrast, specify target values for some variable or combination of variables that the $\mathrm{CB}$ can influence but not directly control, with these values obtained (at least in the work of Svensson) by optimal control exercises on the basis of a designated model and objective function. Thus the specification of a target rule amounts logically to the selection by the analyst of a model and an objective function, whereas an instrument rule reflects the analyst's hypothesis 
that the CB would (whatever its model and objectives) achieve satisfactory results if it were to implement the rule. ${ }^{40}$

It has been emphasized that models represented by the system (1)-(3) specify slowly adjusting price levels. Thus central-bank policy actions, represented by changes in $\mathrm{R}_{\mathrm{t} .}$, typically have effects on real output, $\mathrm{y}_{\mathrm{t}}$. It is of some importance to ask, then, what is the scientific justification for models of this type in preference to ones (including RBC models) in which monetary policy actions have no systematic effects on real variables. Is it theory or empirical evidence that indicates that prices are sticky and monetary policy able to influence output $?^{41}$

Here the argument is much the same as that of Section 2 above-the answer must be empirical evidence since neoclassical theory certainly does not entail price stickiness. But then the question becomes, what type of evidence has indicated strongly and clearly that sticky prices and monetary effects on real variables are a feature of actual economies? For it is unclear how to look for the former, empirically, and there is no shortage of empirical studies that fail to find major effects of the latter type (e.g., Eichenbaum and Singleton (1986)). Regarding sticky prices per se there is some survey evidence provided by Blinder (1994) and studies of particular commodities by others but it is my impression that most analysts have judged these to be non-compelling. More influential, I believe, has been the perception that sharp major changes in monetary policy conditions (e.g., in the United States during 1981) have in fact had major real effects in the same direction, together with the belief that price stickiness provides the most satisfactory means of rationalizing that fact. Ironically, the empirical study that has 
probably attracted the most support for this viewpoint is Romer and Romer (1989), a study that, like Hoover and Perez (1994), I find rather unsatisfactory. ${ }^{42}$

One source of difficulty in formal empirical studies of monetary policy effects on real variables has been the common practice of focusing attention on real responses to policy innovations-i.e., unexpected components - in vector autoregression (VAR) studies. Although Christiano, Eichenbaum, and Evans (1998) have reported effects of this type in an extensive study, they are not quantitatively large in many VAR studies. But the VAR approach seems inherently to miss the major effects, because the measured innovation component of policy-variable fluctuations is extremely small relative to the systematic component in terms of variability. Thus, for example, the systematic component's variability is about 16 times as large as for the innovation component in an estimated interest rate policy rule for the U.S., 1955-1996 (quarterly data). One way of making the relevant point is by consideration of an extreme case. Suppose that a central bank's policy rule is activist but entirely systematic, i.e., is devoid of random components. Then a well-designed VAR study would attribute no importance to monetary policy in affecting output_or inflation! - although it could be that the systematic component of policy was in fact very important.

A related point concerns the way in which empirical evidence works in persuading specialists in monetary economics (and, probably, other areas). In that regard it is almost never the case that an analyst's view on some important hypothesis is crucially dependent upon the results of a formal econometric study — no single study is decisive. This is in part because conclusions about crucial properties of macroeconomic systems almost always require identification of structural parameters in a well-specified 
model, yet both identification and "correct specification" are exceedingly difficult to achieve in the macroeconomic context, for there is usually some highly dubious feature of any manageable model. Instead, it is the cumulative effect of several econometric studies and/or various bits of evidence obtained in more informal ways, all taken together, that is usually persuasive to an analyst.

This section has argued that monetary policy analysis, like macroeconomics more generally and the practice of monetary policy, has been significantly influenced over the last 25 years by both theoretical and empirical developments. That such is the case is certainly desirable, I would think. Indeed, there is an important sense in which significant scientific progress inevitably requires both theoretical and empirical inputs. Evidence is necessary, obviously, because theories with content may by construction be untrue, i.e., grossly inconsistent with relevant facts. But theory too is necessary, for one can only make sense of facts and measurements within the disciplining context of a theoretical structure that gives these facts some coherence and delineates what is and is not relevant, etc.

\section{Cointegration and Monetary Analysis}

In this section, I would like to take up an issue that is highly pertinent to this paper's theme although it failed to find a place in the above evolutionary discussion. This issue concerns a claim, which appears occasionally in the literature, to the effect that a failure of real money balances, real income, and nominal interest rates to be cointegrated implies the absence of any long run relationship of the type that is necessary for the validity of traditional monetary economics. Cuthbertson and Taylor (1990, p. 295), for example, have expressed the claim as follows: "If the concept of a stable, long- 
run money demand function is to have any empirical content whatsoever, then $\mathrm{m}_{t}$ [i.e., $\log$ money]... must be cointegrated with log prices, log income, and interest rates." Engle and Granger (1987) presented evidence contrary to the cointegration hypothesis; several other researchers have reached the opposite conclusion but only after accepting the presumption that cointegration is necessary for standard monetary analysis.

My objective here is to argue that this presumption is basically mistaken. Of course there is a technical sense in which it is correct: if $\mathrm{m}_{t}-\mathrm{p}_{\mathrm{t}}, \mathrm{y}_{\mathrm{t}}$, and $\mathrm{R}_{\mathrm{t}}$ are all integrated (difference stationary) of order one ${ }^{43}$ but not cointegrated, then the disturbance entering any linear relation among them must by definition be nonstationary, so $m_{t}-p_{t}$ and any linear combination of $\mathrm{y}_{\mathrm{t}}$ and $\mathrm{R}_{\mathrm{t}}$ can drift apart as time passes. But it is highly misleading to conclude that in any practical sense a long-run relationship is therefore nonexistent. The following argument is entirely interpretive; it includes no suggestion of technical error in the literature discussed. But that does not diminish its importance.

To develop the argument, let us consider again the example of a traditional money demand function of the form (4). Suppose that $\mathrm{m}_{t}-\mathrm{p}_{\mathrm{t}}, \mathrm{y}_{\mathrm{t}}$, and $\mathrm{R}_{\mathrm{t}}$ are all $\mathrm{I}(1)$ variables and that each has been processed by the removal of a deterministic trend. Then the cointegration status of relationship (4) depends upon the properties of the disturbance term $\varepsilon_{t}$ : if its process is of the difference-stationary type that includes a unit AR root, then the variables in (4) will not be cointegrated.

But the traditional view of money demand theory, as represented by the studies cited above, provides no reason for believing that $\varepsilon_{\mathrm{t}}$ would instead be trend stationary (i.e., would possess no AR unit root component). Indeed, it would seem almost to suggest the opposite-for the theoretical rationale for (4) is built upon the transaction- 
facilitating function of money, but the technology for effecting transactions is constantly evolving. And since technical progress cannot be directly measured by available variables, the effects of technical change (not captured by a deterministic trend) show up in the disturbance term, $\varepsilon_{\mathrm{t}}$. But the nature of technological progress is such that changes (shocks) are typically not reversed. Thus one would expect a priori there to be an important permanent component to the $\varepsilon_{t}$ process, making it one of the integrated type - and thereby making $\mathrm{m}_{\mathrm{t}}-\mathrm{p}_{\mathrm{t}}$ not cointegrated with $\mathrm{y}_{\mathrm{t}}$ and $\mathrm{R}_{\mathrm{t}}$.

In such a case, however, the "long-run" messages of traditional monetary analysis could easily continue to apply. Provided that the magnitude of the variance of the innovation in $\varepsilon_{\mathrm{t}}$ is not large in relation to potential magnitudes of $\Delta \mathrm{m}_{\mathrm{t}}$ values, it will still be true that inflation rates will be principally determined, over long periods of time, by money growth rates. And even without that proviso, long-run monetary neutrality may still prevail, superneutrality may be approximately but not precisely valid, etc. That the disturbance $\varepsilon_{t}$ is of the difference-stationary class is simply not a source of embarrassment or special concern for supporters of the traditional theory of money demand, some of whom have estimated money demand relations like (4) after assuming that $\varepsilon_{\mathrm{t}}$ is a pure random walk $!^{44}$

\section{Conclusion}

The picture painted in the preceding discussion is one that attributes major changes in the analysis and practice of monetary policy over the years 1973-1998 to a combination of theoretical and empirical influences. This is not a very dramatic conclusion; indeed, one might say that it is almost empty. It would be possible to add a bit of debatable content, by asserting that the mixture of influences has been reasonably 
appropriate—about the right amount of theory and empirics—but I would not feel comfortable in doing so. Partly that is because I would have preferred that models with complete price flexibility had not been quite so dominant during the years (say) 19821992, although the surge of work with sticky price models in recent years may have largely made up for their previous neglect. But an equally important reason stems from the question: what type of evidence could be presented in support of a "reasonably appropriate" contention? Unfortunately, I know of no satisfactory way of making such a determination, especially since most influential studies involve a blend of theory and evidence. For example, the rather abstract theoretical analysis of Lucas (1972a) was not actually devoid of empirical content in the sense that its theorizing was specifically designed to rationalize a set of broad facts that were (and are) of genuine, fundamental importance. Consequently, I am left with the rather limp conclusion with which this paragraph began.

In conclusion, then, it may be appropriate to add the opinion that the current state of monetary economics is not as highly unsatisfactory as has been claimed over the past decade or so by various commentators at conferences and seminars. The type of claim that I have in mind does not often make it into print, so I cannot provide citations, but I am confident that many readers can supply examples from their own experiences. In any event, the state of monetary economics seems to me to be about as healthy as that of economic analysis in general. The contrary opinion is rather widely held for three reasons, I would suggest, none of which is sound. First, much of the negative opinion has been put forth by economists who are themselves proponents of an entirely unsatisfactory theory of money demand, one involving overlapping generations models in which the 
asset termed "money" plays no role as a (transaction facilitating) medium of exchange. Since this role provides the defining characteristic of money, as distinct from other assets, it is not surprising that proponents of such a theory would find it unsatisfactory. Second, rather inconsequential differences among proponents of the transaction-facilitating approach to money demand theory-e.g., cash-in-advance, money-in-utility function, shopping time, or transaction-cost-in-budget constraint models-have tended to obscure the fundamental similarity of principles and implications among the variants of this approach. Third, the profession's poor level of understanding of the precise nature of the dynamic connection between monetary and real variables-i.e., of price adjustment relations - has tended to reflect discredit upon monetary economics, although this relation belongs to the realm of macroeconomics more broadly. In that regard, moreover, it is an illusion to believe that macroeconomics is itself in poor condition in relation to microeconomics, an illusion generated by the fact that applied macro features a much more ambitious agenda than applied micro - the understanding of quarter-to-quarter dynamic movements in variables rather than just steady state values. Correcting for that difference, the extent of disagreement seems about the same in the two sub-disciplines. 


\section{References}

Alogoskoufis, G.L., and R. Smith (1991) "The Phillips curve, the persistence of inflation, and the Lucas critique," American Economic Review 81, 1254-1275.

Altug, S. (1989) “Time-to-build and aggregate fluctuations," International Economic Review 30, 889-920.

Axilrod, S.H. (1983) “A comment on Brunner and Meltzer," Carnegie-Rochester Conference Series 18, 105-112.

Barro, R.J. (1977) "Unanticipated money growth and unemployment in the United States," American Economic Review 67, 101-115.

Barro, R.J., and D.B. Gordon (1983) "A positive theory of monetary policy in a natural rate model," Journal of Political Economy 91, 589-610.

Basu, S. (1996) "Procyclical productivity: increasing returns or cyclical utilization," Quarterly Journal of Economics 111, 719-751.

Bernanke, B.S., and F.S. Mishkin (1997) "Inflation targeting: A new framework for monetary policy?"

Blinder, A.S. (1994) "On sticky prices: academic theories meet the real world," Monetary Policy, ed. N.G. Mankiw. Chicago: Univ. of Chicago Press.

Brayton, F., A. Levin, R. Tryon, and J.C. Williams (1997) "The evolution of macro models at the Federal Reserve Board," Carnegie-Rochester Conference Series on Public Policy 47, 43-81.

Broaddus, A., and M. Goodfriend (1984) "Base drift and the longer-run growth of M1: Experience from a decade of monetary targeting," Federal Reserve Bank of Richmond Economic Review 70 (Nov./Dec.), 3-14. 
Brunner, K., and A.H. Meltzer (1983) "Strategies and tactics for monetary control," Carnegie-Rochester Conference Series 18, 59-104.

Burns, A. (1979) “The real issues of inflation and unemployment," Federal Reserve Readings on Inflation. Federal Reserve Bank of New York.

Bryant, R.C., P. Hooper, and C.L. Mann (1993) Evaluating Policy Regimes: New Research in Empirical Macroeconomics. Washington: Brookings Institution.

Calvo, G. A. (1983) "Staggered prices in a utility prices in a utility maximizing framework," Journal of Monetary Economics 12, 383-398.

Christiano, L.J., and M. Eichenbaum (1995) "Liquidity effects, monetary policy, and the business cycle," Journal of Money, Credit, and Banking 27, 1113-1136.

Christiano, L.J., M. Eichenbaum, and C.L. Evans (1998) "Monetary policy shocks: What have we learned and to what end?" NBER Working paper 6400. Forthcoming in Handbook of Macroeconomics, ed. J.B. Taylor and M. Woodford.

Cochrane, J.H. (1994) “Shocks,” Carnegie-Rochester Conference Series 41, 295-364.

Cogley, T., and J.M. Nason (1995) "Output dynamics in real-business cycle models," American Economic Review 85, 492-511.

Cuthbertson, K., and M.P. Taylor (1990) "Money demand, expectations, and the forwardlooking model," Journal of Policy Modeling 12, 289-315.

Eichenbaum, M., and K. J. Singleton (1986) "Do equilibrium real business cycle theories explain postwar U.S. business cycles?" NBER Macroeconomic Annual 1986. Cambridge, MA: MIT Press.

Engle, R.F., and C.W.J. Granger (1987) "Co-integration and error correction: representation, estimation, and testing," Econometrica 55, 251-276. 
Ericsson, N., and J. Irons (1995) "The Lucas critique in practice: Theory without measurement," in Macroeconometrics: Developments, Tensions, and Prospects, ed. by K.D. Hoover. Boston: Kluwer Academic Press, 263-312.

Evans, C.L. (1992) "Productivity shocks and real business cycles," Journal of Monetary Economics 29, 191-208.

Feldstein, M. and J.H. Stock (1994) "The use of a monetary aggregate to target nominal GDP,” Monetary Policy, ed. N.G. Mankiw. Chicago: Univ. of Chicago Press.

Friedman, M. (1966) “Comments,” Guidelines, Informal Controls, and the Marketplace, ed. G.P. Schultz and R.Z. Aliber. Chicago: Univ. of Chicago Press. (1968) “The role of monetary policy," American Economic Review 58, $1-17$.

Fuhrer, J.C. (1997) "The (Un)importance of forward-looking behavior in price specifications," Journal of Money, Credit, and Banking 29, 338-350. (1995) "The persistence of inflation and the cost of disinflation," New England Economic Review, Jan/Feb, 3-16.

Gali, J. (1997) "Technology, employment, and the business cycle: Do technology shocks explain aggregate fluctuations? NBER Working Paper 5721.

Goodfriend, M. (1997) "Monetary policy comes of age: A $20^{\text {th }}$ century odyssey," Federal Reserve Bank of Richmond Economic Quarterly 83 (Winter), 1-22.

Goodfriend, M., and R.E. King (1997) "The new neoclassical synthesis and the role of monetary policy,” NBER Macroeconomics Annual 1997, 231-282.

Gordon, R.J. (1970) "The recent acceleration of inflation and its lessons for the future," Brookings Papers on Economic Activity, No. 1, 8-41. 
(1975) "The impact of aggregate demand on prices," Brookings Papers on

Economic Activity, No. 3, 613-662.

Haldane, A.G., ed. (1995) Targeting Inflation. Bank of England.

Hall, R.E. (1978) "Stochastic implications of the life-cycle-permanent income hypothesis: theory and evidence," Journal of Political Economy 86. 971-987.

Hansen, L.P., and K.J. Singleton (1982) "Generalized instrumental variables estimation of nonlinear rational expectations models," Econometrica 50, 1269-1286.

Hendry, D.F. and N.R. Ericsson (1991) "Modeling the demand for narrow money in the United Kingdom and the United States,” European Economic Review 35, 833-886.

Hoover, K.D. (1995) "Facts and artifacts: calibration and the empirical assessment of real business cycle models," Oxford Economic Papers 47, 24-44.

Hoover, K.D., and S.J. Perez, (1994) "Money may matter, but how could you know?" Journal of Monetary Economics 34, 89-100.

Kerr, W. and R.G. King (1996) "Limits on interest rate rules in the IS-LM model," Federal Reserve Bank of Richmond Economic Quarterly 82 (Spring), 47-75.

King, R.E. (1990) “Money and business cycles,” Working Paper. Forthcoming in Journal of Monetary Economics.

King, R.E., and M.W. Watson (1994) "The post-war U.S. Phillips curve: a revisionist econometric history," Carnegie-Rochester Conference Series 41, 157-219.

Kydland, F.E., and E.C. Prescott (1980) "A competitive theory of fluctuations and the feasibility of stabilization policy," in Rational Expectations and Economic Policy, ed. S. Fischer. Chicago: Univ. of Chicago Press. 
(1982) "Time to build and aggregate fluctuations,"

Econometrica 50, 1345-1370.

,"The workweek of capital and its cyclical

implications," Working paper.

Leiderman, L., and L.E.O. Svensson, eds. (1995) Inflation Targets. London: Centre for

Economic Policy Research.

Litterman, R.B., and L. Weiss (1989) “Money, real interest rates, and output: a

reinterpretation of postwar U.S. data," Econometrica 53, 129-156.

Lucas, R.E., Jr. (1972a) “Expectations and the neutrality of money,” Journal of Economic

Theory 4, 103-124.

(1972b) "Econometric testing of the natural-rate hypothesis," The

Econometrics of Price Determination, ed. O. Eckstein. Washington, D.C. Board

of Governors of the Federal Reserve System.

(1973) "Some international evidence on output-inflation tradeoffs,"

American Economic Review 63, 326-334.

(1975) "An equilibrium model of the business cycle," Journal of

Political Economy 83, 1113-1144.

(1976) “Econometric policy evaluation: a critique," Carnegie-Rochester

Conference Series 1, 19-46.

(1988) "Money demand in the United States: a quantitative review,"

Carnegie-Rochester Conference Series 29, 137-167.

Mankiw, N.G., J.J. Rotemberg, and L. Summers (1985) “Intertemporal substitution in macroeconomics," Quarterly Journal of Economics 100, 225-251. 
Marschak, J. (1953) “Economic measurements for policy and prediction,” Studies in Econometric Method, ed. W.C. Hood and T.J. Koopmans. New York: John Wiley.

McCallum, B.T. (1980) "Rational expectations and macroeconomic stabilization policy," Journal of Money, Credit, and Banking 12, 716-746.

(1976) "Rational expectations and the natural rate hypothesis: some consistent estimates," Econometrica 44, 43-52. (1986) "On 'real' and 'sticky-price' theories of the business cycle," Journal of Money, Credit, and Banking 18, 397-414. (1989) "Real business cycle models," Modern Business Cycle Theory, ed. R.J. Barro. Cambridge, MA: Harvard Univ. Press. (1994) “Comment on 'Federal Reserve Policy: Cause and Effect' by

M.D. Shapiro,” Monetary Policy, ed. N.G. Mankiw. Chicago: Univ. of Chicago Press for NBER. (1999) "Issues in the design of monetary policy rules," Handbook of

Macroeconomics, ed. J.B. Taylor and M. Woodford. Amsterdam: North-Holland Pub. Co.

McCallum, B.T., and M. S. Goodfriend (1987) "Demand for money: theoretical studies," The New Palgrave, ed. J. Eatwell, M. Milgate, and P. Newman. New York: Stockton Press.

McCallum, B.T., and E. Nelson (1998) "Nominal income targeting in an open-economy maximizing model," NBER Working paper 6675. (1997) “An optimizing IS-LM specification for monetary 
policy and business cycle analysis," NBER Working paper 5875. Forthcoming in Journal of Money, Credit, and Banking.

Nelson, C.R., and C.I. Plosser (1982) "Trends and random walks in macroeconomic time series," Journal of Monetary Economics 10, 139-162.

Nelson, E. (1998) "Sluggish inflation and optimizing models of the business cycle," Journal of Monetary Economics 42, 303-322.

Patinkin, D. (1965) Money, Interest, and Prices, $2^{\text {nd }}$ ed. New York: Harper \& Row.

Phelps, E.S. (1967) “Phillips curves, expectations of inflation, and optimal unemployment overtime," Economica 34, 254-281.

Prescott, E.S. (986) “Theory ahead of business cycle measurement,” Carnegie-Rochester Conference Series 25, 11-44.

Romer, C.D., and D. Romer (1989) "Does monetary policy matter? A new test in the spirit of Friedman and Schwartz,” NBER Macroeconomics Annual 1989, 121-170.

Rotemberg, J.J. (1982) "Monopolistic price adjustment and aggregate output," REStud 44, 517-531.

Rotemberg, J.J., and M. Woodford (1997) “An optimization based econometric framework for the evaluation of monetary policy," NBER Macroeconomics Annual 1997, 297-345.

Sargent, T.J. (1971) “A note on the accelerationist controversy,” Journal of Money, Credit, and Banking 3, 50-60. (1973) "Rational expectations, the real rate of interest, and the natural rate of unemployment," Brookings Papers on Economic Activity, No. 2, 429-472. 
Sargent, T.J., and N. Wallace (1975) "'Rational' expectations, the optimal monetary instrument, and the optimal money supply role," Journal of Political Economy $83,241-254$.

Sims, C.A. (1980) “A comparison of interwar and postwar business cycles: monetarism reconsidered," American Economic Review Papers and Proceedings 70, 250-257.

Solow, R.M. (1969) Price Expectations and the Behavior of the Price Level. Manchester: Manchester Univ. Press.

Svensson, L.E.O. (1997) "Inflation forecast targeting: implementing and monitoring inflation targets," European Economic Review 41, 1111-1146.

Taylor, J.B. (1980) “Aggregate dynamics and staggered contracts,” Journal of Political Economy 88, 1-23.

(1989) "Monetary policy and the stability of macroeconomic relationships," Journal of Applied Econometrics 4, S161-178.

(1993) “Discretion versus policy rules in practice," Carnegie-Rochester Conference Series 39, 195-214. (1996) "How should monetary policy respond to shocks while maintaining long-run price stability—conceptual issues," Achieving Price Stability, Federal Reserve Bank of Kansas City. (1998) "The robustness and efficiency of monetary policy rules as guidelines for interest rate setting by the European Central Bank," Working paper. Tobin, J. (1969) “Discussion,” Inflation: Its Causes, Consequences, and Control, ed. S.W. Rousseas. New York: New York University. Walsh, C.E. (1998) Monetary Theory and Policy. Cambridge, MA: MIT Press. 
Walters, A.A. (1971) "Consistent expectations, distributed lags, and the quantity theory," Economic Journal 81, 273-281.

Watson, M.W. (1993) “Measures of fit for calibrated models," JPE 101, 1011-1041.

Woodford, M. (1995) "Price-level determinacy without control of a monetary aggregate," Carnegie-Rochester Conference Series 43, 1-46. 


\section{Endnotes}

1 A different (but not incompatible) account of post-Bretton Woods developments in monetary analysis is provided by Goodfriend and King (1997), who coined the term "new neoclassical synthesis."

${ }^{2}$ A very brief analysis of the source of the collapse is given below in Section 3.

3 One reason, perhaps, is that Walters used a different term, namely, "consistent expectations." His paper's first footnote states in part: "What I call consistent expectations is formally similar to Richard Muth's rational expectations." Actually, of course, Richard F. Muth - at the time a leading scholar in the field of housing economics-is the brother of John F. Muth.

${ }^{4}$ On the latter, see McCallum (1980).

${ }^{5}$ A variant is the claim that it is implausible that all agents would believe in the same model of the economy. But, first, this is an objection to macroeconomics, not rational expectations, and second, there are some rational expectations models in which agents' expectations are not all alike.

6 This statement oversimplifies greatly, in several respects. First, Kydland and Prescott (1982) was clearly previewed by Kydland and Prescott (1980). Second, there were important early contributions by other RBC analysts, including King, Long, Plosser, and Rebelo - and, as stated below, RBC analysis developed out of earlier work by Lucas, Barro, Sargent, and others. Third, the rise of RBC analysis was somewhat more gradual than the exposition in the text indicates.

${ }^{7}$ A partial exception was work involving unit-root or cointegration analysis, which was quite popular. But this work lay more in the domain of econometrics than macroeconomics, and besides there were prominent issues concerning this topic's relation to RBC analysis-see, e.g., Nelson and Plosser (1982).

${ }^{8}$ The first of these papers of which I am aware is King (1990). Other notable efforts with publication dates prior to 1997 include Benassy (1995), Cho (1993), Cho and Cooley (1995), Cooley and Hansen (1995), Hairault and Portier (1993), Kimball (1995), King and Watson (1996), Rotemberg (1996), Ohanian, Stockman, and Kilian (1995), and Yun (1996). For references and a useful review, see Nelson (1998). Some more recent studies will be mentioned below.

9 This statement has been disputed by several readers, and I must confess that the following argument is not entirely straightforward. But I continue to believe that the 
leaders of the RBC movement were not Keynesians who were won over by arguments for theoretical purity, but instead were adherents of the Lucas-Barro equilibrium approach who discovered that it was very difficult empirically to assign much importance to monetary shocks.

10 This is not to imply that these studies are immune to criticism; in fact I have quarreled with some of them myself. But the point is that, rightly or wrongly, they were influential.

11 One reader has suggested that it is illogical for me to cite "evidence" as providing stimulus for the rise and also the decline of RBC analysis. But I contend that this is not illogical, for different types of evidence were predominant during the two phases of intellectual development.

12 Actually, the lead and lag correlations appeared somewhat later, in Kydland and Prescott (1986).

13 See, for example, Hoover (1995) and the symposium, with articles by Kydland and Prescott, Hansen and Heckman, and Sims, in the Winter 1996 issue of the Journal of Economic Perspectives.

14 The other nations at Bretton Woods would never have agreed to a system based on a paper dollar standard.

15 An interesting document in this regard is Burns (1979), a speech given in 1975.

16 One account that is more detailed but basically consistent with the one given here is Goodfriend (1997).

${ }^{17}$ In my opinion it is entirely clear that the above-optimal inflation of the 1970s cannot plausibly be attributed to the time-inconsistency motivation depicted in the famous analysis of Barro and Gordon (1983); for this model requires that central bankers believe that the public forms its expectations rationally. In fact, central bank policymakers and economists both exhibited considerable hostility to the hypothesis of rational expectations until the middle 1980s.

18 Targets were announced for several money stock measures, which often gave conflicting signals, and target misses were treated as irrelevant bygones during the 1970s.

19 For additional discussion of the 1979-1982 period, including a tabulation of the adjusted M1 growth rates that the FOMC was using at the time (which reveal the tightening during 1981 more clearly than unadjusted values), see Broaddus and Goodfriend (1984). 
${ }^{20}$ Among the reviews of inflation targeting are Haldane (1995), Leiderman and Svensson (1995), and Bernanke and Mishkin (1997).

${ }^{21}$ Since the election of 1996 , the target band has been widened to 0-3 percent.

${ }^{22}$ See, for example, King and Watson (1994).

${ }^{23}$ Such as the IMF or the economic policy institutes of (e.g.) Germany.

${ }^{24}$ This is a slight exaggeration, since reference to simulation results obtained with Fed models will signal a Federal Reserve author, etc. But the methods and the general characteristics of the models used are extremely similar.

${ }^{25}$ It might also be noted that Alan Blinder and Frederic Mishkin are listed as professors but would recently have been categorized as central bank officials.

${ }^{26}$ In this case one bit of evidence is provided by the interchange between Brunner and Meltzer (1983) and Axilrod (1983).

${ }^{27}$ Special mention might be made of former students of John Taylor, including Joseph Gagnon, Andrew Levin, Volker Wieland, and John Williams.

${ }^{28}$ Averaged over numerous replications for each model plus rule specification.

${ }^{29}$ By the output gap I mean the percentage (or fractional) difference between output and its market-clearing, natural-rate, or capacity value. These concepts are subtly but significantly different from model to model.

30 The King-Wolman and Henderson-Erceg-Levin papers have models compact enough that analytical solutions are used rather than stochastic simulations.

31 The point had been made earlier — e.g., in Lucas (1972a) and Sargent (1971)—but was brought out forcefully and at length in Lucas (1976).

32 More precisely, these conditions that relate real money balances to a transaction quantity variable and an opportunity cost variable are obtained by combining first-order optimality conditions with respect to current consumption and money holdings. There is another construct that could more properly be termed a money demand function, but it would include an infinite sequence of expected future values of all variables taken parametrically by the household, so has a very different specification. On all this, see McCallum and Goodfriend (1987).

33 Using the Phillips curve as its laboratory, Alogoskoufis and Smith (1991) find dramatic confirmation of Lucas critique effects. 
${ }^{34}$ Another response is that model mispecifications are likely to yield results spuriously suggesting the importance of lagged variables.

${ }^{35}$ It should be mentioned, perhaps, that a failure to satisfy the NRH is not the same thing as the absence of monetary superneutrality.

36 Indeed, the Fed's major new quarterly econometric model was constructed without any money demand function or any reference to any monetary aggregate—see Brayton et al (1997).

${ }^{37}$ More accurately, it has been assumed that real balance terms should be included in principle but are of negligible importance practically; the classic reference on this is Patinkin (1965).

${ }^{38}$ My own candidate for the weakest component in a macroeconomic model is the priceadjustment (Phillips curve) sector. In McCallum (1999, fn. 14) the argument is stated as follows. "It is not just that the economics profession does not have a well-tested quantitative model of the quarter-to-quarter dynamics, the situation is much worse than that: we do not even have any basic agreement about the qualitative nature of the mechanism. This point can be made by mentioning some of the leading theoretical categories, which include: real business cycle models; monetary misperception models; semi-classical price adjustment models; models with overlapping nominal contracts of the Taylor variety or the Fischer variety or the Calvo-Rotemberg type; models with nominal contracts set as in the recent work of Fuhrer and Moore; NAIRU models; Lucas supply function models; MPS-style markup pricing models; and so on. Not only do we have all of these basic modeling approaches, but to be made operational each of them has to be combined with some measure of capacity output - a step that itself involves competing approaches - and with several critical assumptions regarding the nature of different types of unobservable shocks and the time series processes generating them. Thus there are dozens or perhaps hundreds of competing specifications regarding the precise nature of the connection between monetary policy actions and their real shortterm consequences. And there is little empirical basis for much narrowing of the range of contenders."

39 Some representatives are Bryant et al (1993), McCallum (1999), and Taylor (1998).

40 There is also a major controversy as to whether a CB can implement a rule of the "committed" or "non-discertionary" type. Since my own affirmative position on this issue (e.g., McCallum, 1999) is somewhat unorthodox, I propose not to discuss it in the present paper. 
41 There is small but significant school of thought that attributes real effects of policy to financing constraints in flexible-price models, e.g. Christiano and Eichenbaum (1995). Discussion of this position is beyond the scope of the present paper.

42 It is obvious that the Romer and Romer ( $R \& R$ ) dummy variable is not exogenous, for it reflects actions taken in response to recently-prevailing macroeconomic conditions. Thus my own summary statement (McCallum, 1994, p. 334) is that their study differs from previous attempts to measure monetary policy effects primarily as follows: "the $R \& R$ dummy reflects changes in only one direction, does not reflect the intensity of policy actions, and is based on statements rather than actions. Thus one is led to wonder how use of this dummy, instead of a traditional measure, constitutes an improvement over prior practice."

43 A time-series variable is integrated of order one, written I(1), if it must be differenced once to obtain a variable that is covariance stationary. This will be the case for an ARMA variable if its autoregressive parameter has a unit root.

44 More generally, I would a priori expect cointegration among basic variables-ones that enter utility or production functions, not their differences - to be quite rare. for behavioral relations typically include disturbance terms that represent unobservable (and thus omitted) variables, which include shocks to preferences and technology. But these shocks would seem likely to include significant random-walk components, as argued above. Thus disturbance terms in behavioral relations should, according to this argument, typically possess unit-root components. 